\title{
Speaking in signs: Communicating the gospel with deaf people in Zimbabwe
}

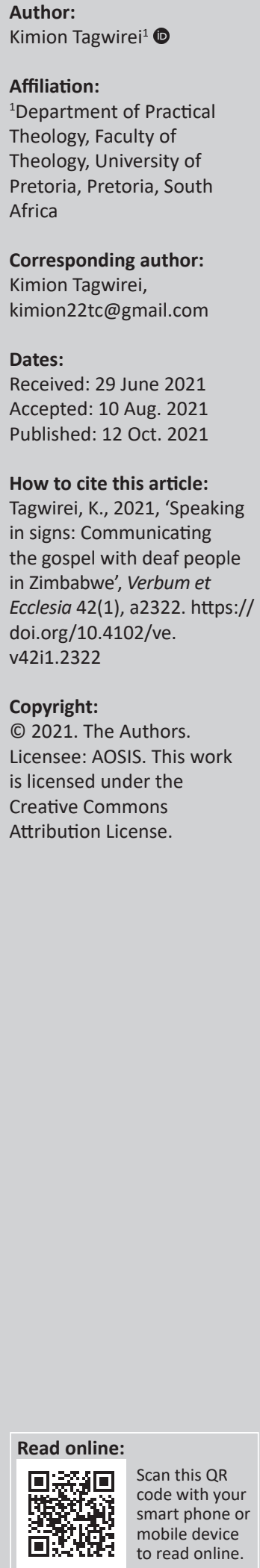

Churches in Zimbabwe have excluded deaf people, limiting their access, presence and participation in Missio Dei and Missio Ecclesiae. So far, there is minimal Zimbabwean theological scholarly attention to communicating the gospel with deaf people. Much of the available related literature focusses on education for deaf people. This article applies a critical disability theory, which is explanatory, practical, normative, and promotes equality and inclusion. In this contribution, communication of the gospel with deaf people is explored. Against the backdrop of marginalisation of deaf people and the inconsideration of the hearing Church, this study interrogated the gospel communication gap that needs to be bridged between deaf people and the hearing Church. The culture of deaf people and communication of the gospel in Zimbabwe were examined. Reflecting through a topic 'Speaking in signs: Communicating the gospel with deaf people in Zimbabwe', using a qualitative research methodology through interviews with 20 participants from different institutions for deaf people and Evangelical Fellowship of Zimbabwe, this research observed that very few denominations have reached out to deaf people with the gospel, whilst the majority have not. The study challenges traditionally exclusive Zimbabwean ecclesiology, missiology and communication of the gospel. It recommends inclusive and contextualised communication of the gospel through the incorporation of sign language and deaf culture towards effective evangelisation and discipleship of deaf people.

Intradisciplinary and/or interdisciplinary implications: The trainers of deaf people, Evangelical Fellowship of Zimbabwe and deaf people themselves provided an example of an interdisciplinary approach to communicating the gospel with deaf people in Zimbabwe where Ecclesiology, Communication and Disability Studies collaborate towards inclusive sharing of the gospel, and the realisation of Missio Dei and Missio Ecclesiae in Zimbabwe.

Keywords: church; communicating; gospel; deaf people; sign language.

\section{Introduction}

For a long time, deaf people have been marginalised, discriminated against and isolated (Ncube 2017; Park 2009:28; Tamez 2007:105) globally and in Zimbabwe by the Church whose culture, language and symbols have remained separated from those of deaf people (Broesterhuizen 2005:308; Lopez 2015). Whilst hearing people listen with their ears, deaf people listen with their eyes and therefore sign language is the 'voice' that they 'hear' through their eyes. The majority of church services and programmes very often exclusively accommodate hearing people. Sign language is rarely used and interpreters are not usually engaged in ecclesiastic communication. Most deaf people are born into hearing families who sometimes come with them to church but only $10 \%$ of families learn enough sign language to communicate effectively (Branch-Smith 2014:1). Deaf people therefore often find themselves being neglected, belittled, and relegated from the gospel (Loomis 2019). Whilst Zimbabwe has institutions such as the Sunrise Sign Language Academy (SSLA), the Henry Murray School of the Deaf and the National Rehabilitation Centre that are commendably offering sign language training, as well as deaf culture and vocational skill development courses, most Zimbabwean churches have not embraced the value and need for promoting sign language and deaf culture to reach out to deaf people with the gospel. Very few church denominations, such as Seventh Day Adventists (SDA), Reformed Church in Zimbabwe (RCZ), True Believers Ministries and Jehovah's Witnesses, have realised the need and established programmes for deaf people. Hearing Christians' inconsideration to communicate the gospel with deaf people has limited the latter's access, presence and participation in church. As a result, the Church appears to discriminate against deaf people (Hitching 2004). Scholarly attention to theological communication to deaf people has been very low in Zimbabwe. There is a wide gap that needs to be bridged between deaf and hearing people, 
in terms of gospel communication. Do they not need the gospel like hearing people? Should they not be part of Missio Dei (mission of God) and Missio Ecclesiae (mission of the Church)? As biblically reflected through Leviticus 19:14 (Thou shall not curse the Deaf, nor put a stumbling block before the blind, but shall fear thy God: I am the Lord), there is a dire need for the Church to accommodate deaf people because they need the gospel like everyone else. This article applied a critical disability theory (Hosking 2008:3), engaged the concepts of communication, Missio Dei, Missio Ecclesiae and interrogated communication of the gospel with deaf people and the need for contextualisation towards inclusive gospel advancement to the unreached communities.

\section{Defining key terminologies}

Communication, gospel and deaf people are pivotal terms that carry the heart of this article. Fatimayin (2018:1) and Fiske (1990:1) present communication as talking to one another. The term communication is originally derived from the Latin word 'communis', which means 'to make common'. It facilitates sharing of experiences with other people (McCornack \& Morrison 2019:104). It involves sharing of ideas, thoughts, feelings or information with others. This article uses the word communication holistically, in concurrence with Fred Jandt (2018) who defines it from a cultural perspective, as:

the means by which individuals learn appropriate behaviours, the means by which those behaviours are regulated and the means by which individuals of one group identity interact with individuals of other group identities and the general way through which different groups interact with one another. (p. 73)

The gospel, comprehensively, refers to good news, good messages, glad tidings, which states that there is a living God who created heaven and earth, teaches salvation through Jesus Christ, encourages proclamation of the love and grace of God, gives the promise of the Holy Spirit and eternal life, and advises the inclusivity of salvation (Ofori 2020; Piper 2005:25-35).

Deafness is a complex term that needs clarification. It relates to hearing loss and hardness of hearing. One can define deaf people as those whose sense of hearing is non-functional for the ordinary purpose of life. Sacks (1990:4) explains that deafness can be classified into two groups: congenital - when people are born not hearing, and adventitious - when people are born with hearing but their sense of hearing becomes impaired in a later stage of life. The term 'deaf' is so general that it impedes adequate consideration of differing degrees of deafness, which are of qualitative, and even of 'existential' significance. There are the 'hard of hearing' who can manage to hear some speech using hearing aids and a certain amount of care and patience on the part of those who speak to them. There are also the 'severely deaf', who are affected by some ear diseases or injuries in their early life. In the case of those who are hard of hearing, sometimes the hearing of speech may be made possible, especially with new, highly sophisticated hearing aids. There are the 'profoundly deaf', sometimes called 'stone deaf', which are those who have no hope of ever hearing. Mutswanga and Sithole (2014:25) concur and add deaf people have varied hearing losses and use varied means of communication. They use sign language, assistive listening devices or sign language interpreters. In this article, the term deaf is used to mean all people who have varied hearing challenges, people who have their culture with sign language as their major means of communication.

\section{Statement of the problem}

Churches in Zimbabwe have excluded deaf people from its services and programmes and thereby have deprived them of the gospel for ages. Churches, in their inconsideration towards deaf people, neglect sign language and deaf culture and thus exclude them from Missio Dei and Missio Ecclesiae. Consequently, deaf people feel belittled, unnoticed and relegated from the Christian faith. A few denominational initiatives that have been developed for deaf people are led by hearing people whose continued leadership is commendable, and regrettable, because positively it spreads the gospel and, at the same time, negatively distances deaf people from total inclusion by not liberating them to take up leading positions in advancing the gospel amongst each other. Because sign language is a second language for hearing people, their signing will not be as effective as deaf people's. Deaf people appreciate having hearing people signing with them but need empowerment and freedom to evangelise, disciple and develop each other with the gospel. This article probed into ecclesiastic communication with deaf people highlighting the need for contextualisation, evangelisation, discipleship and edification of deaf people to communicate the gospel amongst themselves locally and beyond Zimbabwean borders.

\section{Research methodology}

A qualitative approach was used to accomplish this study. The approach is defined by Yin (2016:9) that it involves studying the meaning of people's lives, as experienced under real-world conditions. Qualitative research captures people's perspectives in their native contexts. It will generate the information that is representative of the realities of people who have real-life experiences and not any preconceptions and assumptions held by the researcher.

The qualitative approach was utilised to elicit data for the study because it yields rich data with descriptions and examples in participants' own experiences and expressions (Leavy 2017:19). In this case, qualitative research involved deaf people and people working with deaf people in reviewing communication and how hearing Christians can communicate the gospel with deaf people in Zimbabwe in the best way possible. Employing this approach is further supported by Hancock, Ockleford and Windridge (2009:7) who say that qualitative research is concerned with developing explanations of social phenomena. The approach 
enabled the researcher to investigate and conceptualise the social world of deaf and hearing people, and the challenges they face in communication.

Interviews were conducted to obtain data. Hancock et al. (2009:16) assert that interviews accommodate a number of open-ended questions based on the research topic. The open-ended nature of the questions provided opportunities for both the interviewer and interviewees to discuss issues in detail. Seidman (2006:9) postulates that interviews help to obtain answers to questions and facilitate understanding of the lived experiences of people. The researcher engaged 20 people from the Evangelical Fellowship of Zimbabwe (EFZ) in Harare, the Henry Murray School of the Deaf in Masvingo, the National Rehabilitation Centre in Ruwa, the Danhiko Project in Harare, SSLA in Harare, and the Leonard Cheshire Disability Trust in Harare. The researcher held an in-depth interview with one student who was born hearing and that later became deaf in Epworth, Harare.

\section{Understanding deaf people in their cultural context}

In the attempts to understand deaf people towards communicating the gospel with them in Zimbabwe, this section reviews literature and engages with the views of interviewed participants to present deaf people from their own cultural context. Deaf people are people living with different hearing challenges as deafness presents various limitations. Engaged participants concurred that deaf people in Zimbabwe are generally very friendly although some of them can be somewhat different when exposed to the insensitiveness of hearing communities. Unlike misunderstandings of most hearing people who feel that deaf people are disabled because they do not have a sense of hearing, deafness is universally not a disability (Hitching 2004; Park 2009:29). Although deaf people cannot hear, they can communicate in sign language and some of them use hearing aids. According to deaf people's cultural perspective, a sense of hearing is not necessary for them. Park (2009) explains that:

$[F]$ or most profoundly deaf people, to be deaf is not to not hear, but a social relation - that is, a relation with other human beings, hearing and Deaf. What the Deaf person sees in other people is not the presence or absence of hearing, not their soundness or their silence, but their mode of communication signing, or moving lips. A Deaf person communicates with Deaf people in sign language. When the Deaf person meets hearing people, he or she may not communicate well with hearing people using an oral method because his or her oral speech is not good. Should hearing people think that such a person is a disabled person? (p. 30)

I agree with Park (2009:30) who argues that if hearing people regard deaf people as disabled just because they cannot use oral language, then they should realise that they are also disabled because they do not know sign language. The argument is based on an understanding that deaf people use sign language as their vernacular language and their challenges with oral language should not be taken as a disability. It must be taken as their nature.

Thus, deaf people do not perceive themselves as people needing to be pitied. They do not see themselves as somehow broken and in need to be fixed. They look at themselves culturally. Culturally, they are a unique and special people, whose experiences are different from those of hearing people, but they are not inferior to hearing people. Their worldview is distinct from that of hearing people but not inadequate. Their native sign language is not a poor version of other languages, but a rich language comprising nuance and expressive complexity (Park 2009:31). What appears disturbing and patronising is the Church's inconsideration to appreciate such a community's cultural status. It is disempowering to deny their right and ability to be what they are. It is important that churches in Zimbabwe should stop treating deaf people as disabled because they cannot use oral languages. The Church should realise that if it cannot use sign language and expects deaf people to speak orally, the Church itself is disabled and unable to communicate the gospel with deaf people. In concurrence with Park (2009:31), deaf people have a distinctive culture that constitute their own ecclesial community, bound together by the Holy Spirit, shared language and experiences. As with other cultural communities, it is important to raise deaf disciples, pastoral ministers and leaders from within their communities.

Many deaf people view their challenged status not as a consequence of deafness itself, but a result of the oppressive ways in which the hearing society treats deafness, such as exclusion (Broesterhuizen 2005:312). Defensive hearing people usually argue that this exclusion is not intended. However, whether this is intended or not, the effects of exclusion remain disturbing and retrogressive.

Deaf people are different in accordance with the degree of their hearing challenges. For some, hearing loss is only a secondary aspect of their life. It is agreeably so because when they are with fellow deaf people, their experience is not problematic like in the company of hearing people. Being surrounded with deaf people is mostly lovely as being with one's own people. They share commonalities and their own way of life in a world that is characterised by thinking and communicating in visual images. The concept of 'disability' is, that way, absent from their daily experiences and is not a befitting description of their life. A story of one deaf female pastor, Elizabeth Von Trapp Walker shared by Broesterhuizen (2005:312-313) is enlightening. Pastor Elizabeth had reflections on Psalm 139:13-14:

For it was you who formed my inward parts; you knit me together in my mother's womb. I praise you for I am fearfully and wonderfully made. Wonderful are your works.

She then questioned God:

How could I be fearfully and wonderfully made if I were less than whole? Why did God knit me together in my mother's womb and forgot to give me perfect hearing? Am I damaged goods? ... (p. 312) 
She further struggled with deafness in her Theology classes at seminary, particularly when discussing the Exodus 4:11 passage where God says to Moses, 'Who gives speech to mortals? Who makes them mute or deaf, seeing or blind? Is it not I, the Lord?' Such reflections continued and led to the realisations that deaf people do not normally suffer because they are malformed by God. Neither do they suffer because of God's fault or their sin. The majority of their suffering eventually stems from the ongoing insensitivity of the hearing world, exclusion from the Church and their loneliness in the hearing world. Interestingly, God has done great wonders for deaf people in their 'defective' state. He created them with ears that hear what people say, not just with mechanically assisted hearing aids, but with their whole bodies. According to Broesterhuizen (2005:313), their eyes see joys, pains and sorrows sometimes hidden in words as the ears of their hearts listen and read body language of speakers. They look at and see the whole person as they speak because their 'defective' nature uses their whole being to hear others. Such are golden gifts that they are endowed with, and they have them because they cannot hear. We can therefore look at deafness as a gift from God. That is befitting because they are fearfully and wonderfully made in their different nature. Deaf Christians live well with their deafness by realising that God singled them out for a special purpose. God gave them the ability to listen with their eyes and to perceive the beauty of his creation in a different light.

The statistics by the Zimbabwe National Association of the Deaf show that Zimbabwe has over 1.5 million people who are deaf and hard of hearing. Deaf people come from all sorts of backgrounds. They have different socioeconomic statuses, races, ethnicities, education levels religions and political affiliations. However, many of those born deaf or who become deaf from an early age become demographically disparate by adulthood. For those who are deafened after hearing is established, the world may remain full of sounds although they appear phantasmal. If hearing is absent at birth, or lost in infancy before language is acquired, or when so afflicted, the prelingually deaf are in a category qualitatively different from all others. Having never heard, they hardly have auditory memories, images or associations. For such people, there can seldom be any illusionary sound. They live in a world of unbroken soundlessness and silence. Their situation and predicaments are therefore unique.

Furthermore, deaf people usually commune, marry and love to live on their own. Chimedza (1997:7) explains that most deaf people marry other deaf people, and statistics show that $85 \%$ of marriages by deaf people are endogamous. They are more comfortable around another deaf person who understands deaf culture and shares the same experiences. In Zimbabwe, many deaf children go to separate schools for deaf children and spend most of their time with other deaf children with limited exposure to hearing children. In adulthood, they continue socialising in the communities of deaf people. Consequently, they develop together in their social, cultural and communication values. Deaf people who live with hearing families often face varied psychosocial problems because of language barriers.

For any life developments, if engaged in their cultural context deaf people are highly educable (Sacks 1990:11). Many of them have remained despised, neglected and practically denied of their human status and church inclusion because they have not been well engaged and empowered. Mutswanga and Sithole (2014:25) state that deaf people use varied means of communication that hearing people can embrace to engage them. They use Zimbabwe Sign Language (ZSL), written and signed English or a combination of all of them, depending on individual degree of deafness, background, education and experience. Sign language is a visual, gestured language that is the first language used by people who are usually profoundly deaf. It is communicated at face-to-face level, using some non-manual features like mouthing, eyes, checks and facial expressions.

Zimbabwe Sign Language has been legalised to be a language in its own right. Some researchers in collaboration with the Ministry of Education successfully conducted research in about 10 to 12 years and obtained information, sign language vocabulary from the literate and illiterate, from the rural and urban, from children and adults (Mutswanga \& Sithole 2014:25). Effective engagements with deaf Zimbabwean people can therefore be done in Zimbabwean Sign Language and deaf cultural contextualisation.

\section{Reviewing gospel communication with deaf people in Zimbabwe}

Whilst church bodies such as EFZ and the Zimbabwe Council of Churches (ZCC) have been talking of implementing recommendations of the World Council of Churches Ecumenical Disability Advocates Network and have been calling for churches to embrace people with disabilities and facilitate their engagement (Chipaka 2020), very few churches in Zimbabwe have made tangible efforts to communicate the gospel with deaf people. The United Methodist Church has begun some ministry work for deaf people (Chikwanah 2019). The Reformed Church in Zimbabwe, which owns the Henry Murray School of the deaf in Masvingo, has produced one deaf pastor (Mswazie 2017) and initiated empowerment for deaf people. Seventh Day Adventists, in partnership with SSLA, opened some services for deaf people (Ncube 2017). Jehovah's Witnesses have established services for deaf people and recently released the first Sign Language Bible book of Mathew (NewsDay 26 January 2021). In an interview for this research, EFZ Secretary General, Reverend Blessing Makwara revealed that most evangelical and Pentecostal churches in Zimbabwe have not engaged deaf people. The few mentioned programs (mostly of mainline denominations) are still only accessible to deaf people through interpreters, as few liturgists can sign well. Much sign language and culture training is still a work in progress. That all the observed services set for deaf people are still facilitated 
by hearing people, distances deaf people from total inclusion. Communication is best done when language is comprehensively utilised. Hearing people who facilitate few identified services for deaf people use sign language as a second language, and their signing capacity is limited and therefore less effective. Those who engage interpreters lose some information along the communication process as interpreting is prone to omissions, distortions and exaggerations that historically characterise oral tradition. Whilst their attempts are highly commendable, effectiveness can only be realised when deaf people are empowered to communicate the gospel to each other in their day-to-day sign language, relating their conversations to their common life experiences. Deaf people may continue to feel excluded and like outsiders until they are fully liberated to lead their services and programmes: worship, preach, sing and do church on their own without interruptions of hearing people whose facilitations tend to attract hegemonic impressions. Churches in Zimbabwe therefore need to reconsider sign language, deaf culture and communicate the gospel with deaf people until they are transformed and entrusted enough to reach out to their fellows on their own as 2 Timothy 2 says (and what you have heard from me before many witnesses entrust to faithful men who will be able to teach others also).

\section{Research findings}

This research found that the majority of churches in Zimbabwe have not yet accommodated deaf people whilst the need for contextualisation of the gospel, understanding the culture and language of deaf people as well as accommodating them by intentionally establishing services and programs for them, is very high. Concurring with Broesterhuizen (2005:307), the interviewed participants said that there is a for contextualisation of the gospel to engage deaf people to redeem them from exclusion. Engaged interviewees pointed out that the gospel has not fully reached deaf people because the language and culture of the traditional Church and the traditional views of the hearing Church on deafness have been disconnected from the culture and daily life experiences of deaf people. The interviewees' views concurred with Loomis (2019) that whilst generally hearing people view deaf people as disabled because they lack a sense of hearing, they are not disabled (Park 2009:29). As Lopez (2015:7) contends, deaf people are just a linguistic minority sharing a unique culture and a common experience. Although they cannot hear, they can communicate in sign language. The cultural perspective of deaf people is that a sense of hearing is not necessary. When a deaf person is in a hearing community, he or she may sometimes feel disabled. In the deaf community, there is no disability, as fellowship, communication, culture and perceptions flow freely. This research showed that gospel communication with deaf people in Zimbabwe may become effective when the Church evangelises, baptises, disciples and develops deaf people as differently able to become pastors, elders, deacons and liturgists like everyone else.

The Evangelical Fellowship of Zimbabwe leaders, the National Rehabilitation Centre senior lecturers and most other engaged interviewees emphasised the need to inclusively and intentionally share the gospel and grow deaf people in faith, arguing that the gospel is biblically inclusive. They agreed with Lopez (2015:29) who observed that deafness should not be seen as a curse or an obstacle for faith development, but as a fertile context in which faith development and theological reflection can take place. Deafness is not a curse. Some biblical reflection on John 9:2-3 depicts supportive lessons. 'Rabbi, who sinned, this man or his parents? It is so that the works of God might be made visible through him'. Jesus Christ's response portrays that disability is not a curse, but a condition for the manifestation of God. For the majority of participants, the Church's message must therefore be contextualised in deaf communities. Instead of imposing hearing people's cultural views, it was observed in concurrence with Broesterhuizen (2005:326) that evangelisation demands penetrating into the roots of the target group's culture, planting seeds of the word, growing and transforming engaged lives. All the interviewees concurred that it is essential for the Church to contextualise the gospel. They said that the Church ought to understand that inculturation is not merely adaption of faith proclamation and liturgy. They viewed it as not only a strategy to make Christianity appealing. They argued that inculturation should be perceived as lovely appreciation of, and engagement with particular groups of people, such as deaf people.

The trainers of deaf people from engaged institutions explained that churches in Zimbabwe need to engage and accommodate deaf people, and this can only be done when it understands that deaf people are bicultural. For them, deaf people are members of mainstream culture whilst also belonging to deaf culture. The trainers noted that there is a tendency of misconstruing all deaf people as homogeneous. According to the Zimbabwean trainers, deafness is not a fixed prescription for a fixed lifestyle or abilities. This is reminiscent of Chimedza (1997:4) who observed that all deaf individuals make unique adjustments to living in accordance with their varying degrees of deafness and their reactions to different social environments. Some deaf people are members of deaf culture whilst others are not. Former Zimbabwe National Rehabilitation center student, Hilary Yafeti who was born hearing, but later accidentally became deaf when a seed of a fruit tree struck inside his right ear, resulting in both of his ears eventually developing infections, causing loss of hearing, said that deaf people are exposed to different cultures because of individual circumstances, experiences and different personal characteristics. The life experience of Hilary who was born and raised in hearing cultures, but who accidentally became deaf and resultantly had different experiences, explain the cultural differences that deaf people unpredictably find themselves in.

Nevertheless, as noted by Chimedza (1997:4), what makes deaf people a cultural group instead of simply a loose organisation of people with a similar sensory loss is the fact that their adaptation to life includes language. An 
environment created solely by sensory deprivation does not make a culture. This is why we do not have a 'blind culture' although blind people, like deaf people, have a common sensory loss. As Chimedza (1997:4) notes, this is, however, not to say that this circumstantial similarity does not affect blind people. It provides a unifying bond for blind people. Their commonalities as blind people bind them together. They share familiar experiences and similarly face their fate but that does not build up essential elements of culture. This is normally because blind people do not have one native language. Arguably, blindness does not make up a cultural group. The participants of this research from the training institutions unanimously agreed that deaf people are discrete. They voiced that the Church should bear in mind that deaf people have a common sign language that they use to form their own culture. Most of the participants remarked that sign language represents an important value to deaf culture. It is through sign language that their thoughts, values, beliefs and customs are expressed. They use sign language as the vehicle to acculturate themselves. The Zimbabwean Sign Language is a complete language with its own syntax semantics and lexicon that differ from English and native chiShona, isiNdebele, chiZezuru, chiTonga, chiKoreKore, chiManyika, chiKaranga and chiNdau. Sign language operates totally independent of speech and audition. It transmits linguistic information through hands, fingers, bodily and facial features. Sign language provides unity amongst deaf people in Zimbabwe. As well clarified by Chimedza (1997:5), deaf people efficiently convey abstract concepts, depict the complexity of real-world issues and portray their emotions through sign language. The interviewees reiterated Sacks' (1990:44) view that the Church ought to embrace deaf cultures in order to contextually communicate the gospel to and with them, and transform and equip them to reach out to other deaf people on their own.

\section{Towards inclusive gospel communication with deaf people}

Globally, there are approximately 70 million deaf people who use sign language as their primary language. Of all those, 98\% have not been evangelised (Coffey 2019:2). Only 2\% have received the gospel. Amongst the 1.5 million deaf Zimbabweans, less than $2 \%$ are assumed to have received the good news. They do not have access to a church that preaches the gospel in their native language and worship in a way that is relevant to their day-to-day life experiences. Unless the Church brings the good news to them with a contextualised approach, they may not get the opportunity to know and worship the Savior. This study observed that communicating the gospel with deaf people in Zimbabwe is crucial because it fills up a gap that has been forsaken for too long. Continued inattention to deaf people portrays God as a distant God who does not understand sign language, who cannot attend to all kinds of people on earth and who does not care for deaf people (Broesterhuizen 2005:311).

To date, the majority of deaf people in Zimbabwe regard the Church and Christian faith as exclusively for hearing people, secluded from the daily lives, communication and culture of deaf people. For deaf people, the Church speaks a foreign, strange language. The Church appears to be a hearing church incapable of entering into progressive dialogue with deaf people and of reaching them within the context of their own life. The mission of the Church seems too ethereal, so unusual for deaf people, belonging to a far and different world. We therefore find few deaf people attending churches in Zimbabwe, not because they do not exist, or do not want fellowship in Christian faith, but because the hearing Church is not reaching them with the gospel. Commendably, as Jehovah's Witnesses (NewsDay 26 January 2021) have initiated Bible translation into Zimbabwean Sign Language, it gives hope towards having prayers, music, sermons and the whole Bible in Sign Language for the communication of the gospel with deaf people to be eventually accomplished.

Furthermore, effective communication can be realised when the hearing Church facilitates discipleship and empowerment programs for deaf people to evangelise and disciple each other in their own cultural ways. Entinger (2014) posits that deaf people are 'uniquely gifted to evangelize and disciple their own people'. Entinger emphasises that hearing people can be supporters in making this happen, as we need both deaf and hearing people to work together to reach deaf people. It is estimated that there are 400-500 different sign languages around the world. The Bible has not been translated into most of the sign languages. In Zimbabwe, there is no Sign Language Bible yet (except the book of Mathew recently released by Zimbabwean Jehovah's Witnesses alluded to before). There is an essential need for the hearing Church to empower and support deaf people to get involved in gospel communication locally and across the world. This article recommends the Church to value and incorporate sign language, accommodate deaf people and facilitate theological training, mentorship and leadership training for deaf people towards effective gospel communication and advancement with deaf people in Zimbabwe, which will give rise to deaf missionaries to reach out with the gospel to deaf communities around Zimbabwe.

The Bible book of Mark 7:31-35 presents great lessons when Jesus healed a deaf man. The story suggests that some people brought the deaf man to Jesus Christ, and he healed him. Park (2009:33) examines that story and argues that Jesus Christ did not perceive deafness as a disability, because he did not say 'hear and speak', but said 'Ephphatha', which means 'be opened'. To my concurrence, Park explains that Jesus Christ prayed for God's will on deaf people. His healing does not mean that all deaf people must receive the ability to hear and speak, but everyone must accept the will of God. Agreeing with Park (2009:34), physical deafness is not a problem in itself; the problem is that people are not willing to attend to the will of God. Like Park's perception of Jesus' exclamation of 'Ephphatha' as not only to the deaf man and to hearing people of his time, but to all of us today who are somewhat deaf to his word to be opened up to his will, to each other and to ministerial possibilities that deaf people can bring to the Church. The communication gap in Zimbabwe must therefore be bridged for inclusive gospel 
advancement. It is valuable to open up closed communication between deaf people and the hearing Church. The need for sign language, understanding deaf culture, nurturing and helping deaf people to evangelise and disciple other deaf people is thus very pertinent (Reinke 2015:53). Churches in Zimbabwe can also engage and partner with the Bible Society of Zimbabwe to facilitate translating the Bible into ZSL. It can also join hands with Para-church organisations towards empowering deaf people in communicating and advancing the gospel.

Instead of concentrating on healing calls, as some may remain deaf for life, churches in Zimbabwe need to realise that the greatest need of a deaf person is not to hear, but to be saved. If one is saved, they will hear forever in heaven. If we ask deaf people about hearing, most of them may not worry much about that. In an interview, the Leonard Cheshire Disability project officer said that 'we should not worry about hearing for the deaf; it's like being black and worrying about possibilities of becoming white'. Deaf people are worried about embracement of sign language for communication, inclusion in the hearing Church and lovely fellowship. The hearing Church cannot say that it accommodates and loves deaf people if it does not make efforts to communicate with and have them in church. Churches in Zimbabwe therefore need to contextualise the gospel, learn sign language, engage and advance the gospel with deaf people. Deaf people need the gospel to live well on earth and go to heaven, not just to see on earth and miss heaven. As the Bible says through Revelation 21:

$[A]$ nd God shall wipe away all tears from their eyes; and there shall be no more death, neither sorrow, nor crying, neither shall there be any more pain: for the former things are passed away. (v. 4)

We need to bear in mind that in heaven, God will wipe away all tears and all things will become new. In heaven, there will be no more deafness. In heaven, there will be no more burdens of lip-reading and attending to interpreters.

Broesterhuizen (2005:325) aptly advises the Church to come into being in the deaf community by breaking the shackles of deaf people's outsider position by reaching them in the context of their own lives. The Church should approach deaf people not as impaired people with a defect, but as people who have a unique contribution to share with the whole human community. It should empower deaf lay persons and help them to create their Christian community, appreciate and accept deaf people's own language in proclaiming their faith and conducting liturgy. Deafness should not be viewed as an obstacle for faith development, but as a context in which faith development and theological reflection take place. As highlighted before, deafness is not a curse. There is therefore a need for enculturation of the Christian message into deaf culture. Contextualisation enables effectiveness of gospel communication. The participants in this research agreed that faith that does not engage different cultures cannot be fully accepted; hence the need for the hearing Church to contextualise the gospel with deaf people. Deafness and deaf culture should therefore be regarded as fertile soil in which seeds of faith can be planted, watered and grown.

\section{Conclusion}

This article observed that the majority of churches in Zimbabwe have not yet reached out to deaf people with the gospel, and that there is a wide gap that needs to be bridged between deaf people and the hearing Church. There is a dire need for deaf people to be included in Missio Dei and Missio Ecclesiae. It was noted that a few denominations, especially mainline churches, have commendably initiated services and programmes for deaf people, whilst most evangelical and Pentecostal churches in Zimbabwe are yet to communicate the gospel with deaf people. Most trainers serving at the institutions of deaf people suggested that churches in Zimbabwe should consider engaging, empowering and backing deaf people to eventually evangelise and disciple each other. This research outlined the need for contextualisation of the gospel into deaf culture for the accomplishment of communication. Conclusively, this article proposes appreciation, consideration, inclusion and utilisation of deaf people, deaf culture, sign language, their evangelisation, discipleship and empowerment towards effective communication and inclusive advancement of the gospel in Zimbabwe and similar foreign deaf communities.

\section{Acknowledgements Competing interests}

The author declares that they have no financial or personal relationships that may have inappropriately influenced them in writing this article.

\section{Author's contributions}

K.T. is the sole author of this article.

\section{Ethical considerations}

The researcher adhered to the ethics of informed consent, protection of confidentiality and privacy, as well as accuracy and fairness in conducting this research.

Before any interviews were commenced, the researcher fully identified himself as a bona fide PhD student in Practical Theology at the University of Pretoria, carrying out research for an article to be published in an academic journal. The research participants were well informed about the researcher and the objective of the research. Thus, they participated in the research.

The researcher also assured the protection of the participants' confidentiality and privacy, and ensured that those who needed to be anonymous would have their wish respected and that their information would only be used for the publication of this article in an academic journal.

The researcher ensured accuracy and fairness by avoiding fabrication of data or results, avoiding any falsification or manipulation, as well as omitting or exaggerating findings. The researcher handled the data accurately and fairly. 


\section{Funding information}

This research received no specific grant from any funding agency in the public, commercial or not-for-profit sectors.

\section{Data availability}

Data sharing is not applicable to this article as no new data were created or analysed in this study.

\section{Disclaimer}

The views and opinions expressed in this article are those of the author and do not necessarily reflect the official policy or position of any affiliated agency of the author.

\section{References}

Branch-Smith, B., 2014, 'Church access for the deaf', viewed 23 February 2021, from https://www.fredericknewspost.com/news/lifestyle/church-access-for-the-deaf/ article 917b8ae6-bf5c-5108-97fa-3abef9193b7d.html.

Broesterhuizen, M., 2005, 'Faith in deaf culture', Theological Studies 66(2), 304-329. https://doi.org/10.1177/004056390506600204

Chikwanah, E., 2019, 'Zimbabwe church embraces Deaf community', UMC News, viewed 10 February 2021, from https://www.umnews.org/en/news/zimbabwechurch-embraces-hearing-impaired.

Chimedza, R., 1997, 'Deaf culture in Zimbabwe: Existence, reality and implication for education', The Zimbabwe Bulletin of Teacher Education 5(1), 1-12.

Chipaka, Z., 2020, 'Inclusion reaches new level at Zimbabwe Council of Churches Assembly', viewed 10 February 2021, from https://www.oikoumene.org/news/ inclusion-reaches-new-level-at-zimbabwe-council-of-churches-assembly.

Coffey, S., 2019, 'Deaf communities: Making Christ known among the leastreached', viewed 12 February 2021, from https://www.christar.org/Christar\%20 Deaf\%2OBooklet.pdf.

Entinger, C., 2014, 'The deaf, an unreached people unlike any other', viewed 14 February 2021, from https://www.missionfrontiers.org/issue/article/the-deaf.

Fatimayin, F., 2018, 'What is communication?', viewed 20 January 2021, from https:// www.researchgate.net/publication/337649561_What_is_Communication.

Fiske, J., 1990, Introduction to communication studies, 2nd edn., Routledge, London.

Hancock, B., Ockleford, E. \& Windridge, K., 2009, 'An introduction to qualitative research', viewed 15 February 2021, from https://www.rds-yh.nihr.ac.uk/wp content/uploads/2013/05/5_Introduction-to-qualitative-research-2009.pdf.

Hitching, R., 2004, 'Church and the deaf people', viewed 14 February 2021 from $\mathrm{http}: / /$ citeseerx.ist.psu.edu/viewdoc/download?doi=10.1.1.200.2634\&rep=rep1 \&type=pdf.
Hosking, D.L., 2008, 'Critical disability theory', viewed 13 May 2021, from https:// www.lancaster.ac.uk/fass/events/disabilityconference archive/2008/papers/ hosking2008.pdf.

Jandt, F., 2018, An introduction to intercultural communication: Identities in a global community, Sage, London.

Leavy, P., 2017, Research design: Quantitative, qualitative, mixed methods, artsbased, and community-based participatory research approaches, The Guilford Press, New York, NY.

Loomis, S., 2019, 'How to reach the deaf community with the Gospel', viewed 14 February 2021, from https://media.ascensionpress.com/2019/12/13/how-toreach-the-deaf-community-with-the-gospel-\%EF\%BB\%BF/.

Lopez, M.N., 2015, 'To speak the word of god with our hands for those who hear with their eyes', Master's dissertation, Department of Theology, Bellarmine College of Liberal Arts.

McCornack, S. \& Morrison, K., 2019, Reflect \& relate: An introduction to interpersona communication, 5th edn., MacMillan Learning, New York, NY.

Mswazie, W., 2017, Deaf preacher makes wave, Attracts huge following in Masvingo. Takes Gospel to another level, viewed 20 February 2021, from https://www. herald.co.zw/deaf-preacher-makes-waves-\%E2\%80\%A2attracts-huge-followingin-masvingo-\%E2\%80\%A2takes-gospel-to-another-level-\%E2\%80\%A2reformedchurch-revels-in-success/.

Mutswanga, P. \& Sithole, C., 2014, 'Perceptions of people who are deaf on sign language teaching and communication by hearing people', Greener Journal of Education and Training Studies 2(2), 025-037. https://doi.org/10.15580/GJETS. 2014.2.032714167

Ncube, D., 2017, 'SSLA, SDA take religion to the deaf...God is not deaf', Sunday Mail, viewed 21 February 2021, from https://www.pressreader.com/zimbabwe/thesunday-mail-zimbabwe/20151122/281861527410747.

Newsday, 2021, Jehovah's witnesses release sign language Bible, viewed 15 February 2021, from https://www.newsday.co.zw/2021/01/jehovahs-witnesses-releasesign-language-bible/

Ofori, E., 2020, 'The gospel is John 3:16', viewed 20 January 2021, from https://www. researchgate.net/publication/340962705.

Park, M.S., 2009, 'Deaf culture and deaf church considerations for Pastoral Ministry', 21 January 2021, from https://www.scd.org/sites/default/files/2017-07/deafculture-deaf-church.pdf.

Piper, J., 2005, God is the Gospel. Meditations on God's love as the gift of himself, Crossway Books, Wheaton, IL.

Reinke, J., 2015, 'The deaf can hear the word of god', PhD in Ministry, Department of Practical Theology, Concordia Seminary, viewed 23 February 2021, from https:// scholar.csl.edu/dmin/125.

Sacks, O., 1990, Seeing voices: A journey into the world of the deaf, Harper Perennial, A Division of Harper Collins Publishers, New York, NY.

Seidman, I., 2006, Interviewing as qualitative research: A guide for researchers in education and the social sciences, 3rd edn., Teachers College Press, New York, NY.

Tamez, E., 2007, 'The Bible from the perspective of the deaf community', 성경원문연구 35(1), 104-111. https://doi.org/10.28977/jbtr.2007.4.20s.104

Yin, R., 2016, Qualitative research from start to finish, 2nd edn., The Guilford Press, New York, NY. 